not finished, and the accident will hamper continuing projects. "We can only hope that they are able to restore the detector soon," says Art McDonald, director of the Sudbury Neutrino Observatory in Ontario, Canada.

The project that will feel the most immediate impact is ' $\mathrm{K} 2 \mathrm{~K}$ ', which shoots a beam of neutrinos 250 kilometres through the Earth's crust from an accelerator at the High Energy Accelerator Research Organization (KEK) in Tsukuba, north of Tokyo. This Japan-US-Korea collaboration aims to study neutrino 'oscillation', the conversion of neutrinos from one form to another which confirms they have mass.

Neutrinos come in three forms, or 'flavours', and in experimental runs up to April this year, muon neutrinos, the flavour shot from KEK, have been detected by Super-K's sensors 44 times. As this falls short of the 66 expected sightings, the results suggest that the particles are turning into another neutrino variety. "This is an indication, but not conclusive evidence," admits Koichiro Nishikawa, a spokesman for the K2K collaboration.

The plan was to triple the amount of data by 2005, when the proton synchrotron used in the experiment will be shut down. $\mathrm{K} 2 \mathrm{~K}$ was scheduled to start taking data again in January 2002. Totsuka hopes to have Super-K back in action by January 2003. If so, it may be possible to increase data collection from the originally planned six months per year to eight or more months to make up for the lost time.

Totsuka is now trying to find a quick and relatively cheap way to get Super-K back online. The damaged PMTs cost \$3,000 each when they were installed during 1992-96, and Hamamatsu discontinued their production in 1998. One possibility is to halve the number of PMTs. This would reduce Super-K's sensitivity to solar neutrinos and, to a lesser extent, to atmospheric neutrinos. But those released from KEK are of sufficiently high energy for them still to be readily detected.

Totsuka also hopes that the cheaper, more advanced PMTs being developed for a proposed upgrade known as HyperKamiokande, planned to start within a decade or more, might be introduced earlier at Super-K.

The world's neutrino physicists are hoping that the damage to Super-K can soon be repaired. Its absence from the field will be keenly felt, they say. "I am emotionally attached to the Super-K detector," says John Bahcall of the Institute for Advanced Study in Princeton, New Jersey. "It has done things that I only previously dreamed about."

www-sk.icrr.u-tokyo.ac.jp

\title{
Genetics paper erased from journal over political content
}

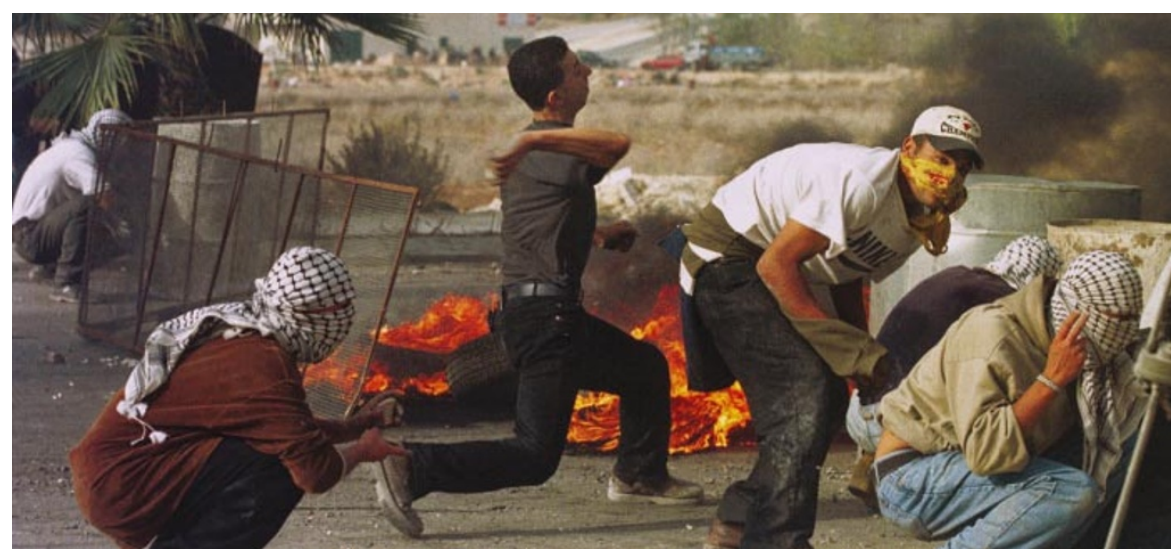

War of words: controversial descriptions of the Israeli-Palestinian conflict led to the article being axed.

\section{Erica Klarreich}

A paper about the genetic origins of Palestinians has found itself at the centre of a political storm. In a highly unusual move, the journal Human Immunology has deleted the paper from its September issue after receiving a wealth of complaints over what some saw as inappropriate political comments about the Israeli-Palestinian conflict.

The paper examines genetic variability in the HLA complex - a highly diverse complex of immune-system genes — in a sample of Palestinians (A. Arnaiz-Villena et al. Hum. Immunol. 62, 889-900; 2001). But controversially, it also includes a historical introduction calling Jews living in the Gaza strip "colonists" and describing some Palestinians as living in concentration camps. The paper's publication sparked a "cascade" of angry letters complaining that such comments had no place in a scientific journal, says the journal's editor-in-chief, Nicole Suciu-Foca of Columbia University in New York.

The paper "purports to be a scientific treatise" but "offers opinion on geopolitical issues that cannot be substantiated by the data presented", wrote Dolly Tyan, then president of the American Society for Histocompatibility and Immunogenetics (ASHI), which runs the journal, in a letter to members on 3 October. "ASHI is offended and embarrassed by its inclusion within the journal."

The publisher of Human Immunology, Elsevier Science, has removed all electronic versions of the article and has sent a letter to individual subscribers and librarians advising them to ignore the article "or, preferably, to physically remove the relevant pages".

The paper's lead author, Antonio ArnaizVillena of the Complutense University in Madrid, says he did not intend to offend anyone and calls the decision to withdraw the article "unwise". He says he has several letters of support, including one from Jean Dausset, president of the Human Polymorphisms Study Centre in Paris, one of the founding fathers of HLA genetics. A more appropriate action, Arnaiz-Villena says, would have been to publish the letters of complaint and allow him to respond.

But the depth of anger the article raised made such a course impossible, argues Suciu-Foca. One ASHI member was so offended by the article that he resigned, she says. "We would have had mass resignations and the journal would have been destroyed if this paper were allowed to remain."

The paper was in a special issue on anthropology edited by Arnaiz-Villena. Although Arnaiz-Villena says the paper was approved by two reviewers, the incident has prompted the journal's editorial board to revise its policy so that in future the editor-in-chief will supervise work by guest editors, Suciu-Foca says.

The data announced in the paper, which indicated that Jews and Palestinians have a close genetic relationship, were worth reporting, says Steven Marsh, a member of Human Immunology's editorial board who studies the nomenclature of HLA genes at the Anthony Nolan Research Institute in London. "Had the authors confined themselves to announcing their scientific results, it would have been an interesting paper," he says.

The retraction of a scientific paper because of political statements is "unprecedented", says Sheldon Krimsky, an expert on publication ethics at Tufts University in Medford, Massachusetts. But the editorial board took legal advice before making its decision, Suciu-Foca says. "This has nothing to do with freedom of opinion," she says. "This journal is not the right forum for expressing political views.”

The editors invited Arnaiz-Villena to resubmit a revised version of the article, SuciuFoca says, and reviewers are now considering a new version for possible publication. 